\title{
LAVOURA ARCAICA, DE RADUAN NASSAR, E “A VOLTA DO FILHO PRÓ- DIGO”, DE ANDRÉ GIDE: UMA LEITURA INTERTEXTUAL
}

\author{
Wilma Santana dos Santos* \\ Maria das Graças Fonseca Andrade
}

RESUMO: Este artigo apresenta uma análise de Lavoura arcaica (1975), romance inaugural do escritor brasileiro Raduan Nassar, mediante os conceitos de dialogismo e polifonia, preconizados por Mikhail Bakhtin (1972), e pelo conceito de intertextualidade, instituído por Julia Kristeva (1969) e discutido pelos críticos literários Perrone-Moisés (1978) e Borges (2007). Com uma escrita singular, Nassar se apossa da narrativa bíblica "A parábola do Filho Pródigo", presente no livro de Lucas, e do conto "A volta do Filho Pródigo", de André Gide, para elaborar algo inovador. Nesse trabalho intertextual, realizado por Nassar em Lavoura arcaica, é possível perceber aproximações e distinções dos textos supramencionados.

PALAVRAS-CHAVE: André Gide; Intertextualidade; Lavoura arcaica; Raduan Nassar; A volta do Filho pródigo.

\section{Considerações iniciais}

Lavoura arcaica (1975), romance inaugural de Raduan Nassar, é um divisor de águas na literatura brasileira. A obra em questão apresenta peculiaridades fundamentais em sua

\footnotetext{
* Mestranda em Letras: Cultura, Educação e Linguagens pela da Universidade Estadual do Sudoeste da Bahia (Uesb).

** Doutora em Literatura Brasileira pela Universidade Federal de Minas Gerais (UFMG). Professora Titular da Universidade Estadual do Sudoeste da Bahia (Uesb).
} 
composição, como a elaboração do enredo, as personagens, o ritmo, que confere musicalidade à narrativa e, sobretudo, o trabalho meticuloso com a linguagem. O estilo incisivo e inovador, perceptível em suas obras, consagrou Nassar como um dos maiores escritores da nossa literatura.

Além de Lavoura arcaica, Nassar escreveu Um copo de Cólera, em 1970, embora só tenha vindo a público em 1978; Menina a Caminho que foi publicada numa edição nãocomercial, em 1994, e alguns contos publicados em periódicos nacionais e estrangeiros. Apesar de o escritor não ter uma vasta produção literária, as suas obras são densas e reconhecidas nacional e internacionalmente. Lavoura arcaica e Um copo de Cólera foram traduzidas para o alemão em 1991, para o italiano em 1982 e, para o francês, em 1985. Já a obra Menina a Caminho foi traduzida para o alemão em 1982.

Aclamado pela crítica, Nassar recebeu, em 1976, o Prêmio Coelho Neto da Academia Brasileira de Letras e o Prêmio Jabuti; recebeu Menção Honrosa na categoria Revelação de autor pela Associação Paulista de Críticos de Arte (APCA); em 1978, foi premiado mais uma vez pela APCA, na categoria Ficção para Um Copo de Cólera; em 2016, foi consagrado com o prêmio Camões e, recentemente, em 2017, foi premiado com o Jabuti na categoria de Livro Brasileiro Publicado no Exterior, com o título "A cup of rage”, pela Penguin Random House.

Ao estrear com Lavoura arcaica, Nassar inovou ao escrever fora dos parâmetros propostos nas décadas de 60 e 70, época na qual diversos escritores estavam empenhados com a produção de uma literatura engajada, ideologicamente compromissada em denunciar as opressões e mazelas sociais do país:

Os anos 70 se impõem sobre os escritores com a demanda de encontrar uma expressão estética que pudesse responder à situação política e social do regime autoritário. É esta responsabilidade social que se transforma numa procura de inovação da linguagem e das alternativas estilísticas às formas do realismo histórico (SCOLLHAMMER, 2009, p. 22-23). 
O Brasil vivia o período de Ditadura Militar, em que o governo censurava todas as produções intelectuais e artísticas que não se adequassem às propostas estabelecidas pelo regime ditatorial. Os escritores da década de 70 passaram a questionar, em suas obras, a forma autoritária do governo como modo de responder à repressão sofrida na época e, devido a isso, muitas dessas obras foram censuradas. Segundo Pellegrini (2008),

De um modo geral, a visão linear sobre a censura à produção cultural durante a ditadura militar, tende a fixar os anos 70 como aqueles em que ela atuou com maior peso, determinando uma espécie de estética do reflexo, na medida em que efetivamente impôs seus "padrões de criação", cortando, apagando, proibindo ou engavetando incontáveis peças, filmes, canções, novelas de TV, artigos de jornal, romances e contos (PELLEGRINI, 2008, p. 38-39).

Apesar do engajamento político das obras literárias produzidas neste período, que possuíam forte caráter panfletário e jornalístico, Raduan Nassar manteve-se à margem do padrão literário da época e com um estilo singular escreveu Lavoura arcaica, essa obra-prima da literatura brasileira. Esta recusa de Nassar à produção engajada da época chamou a atenção da crítica literária:

Li Lavoura arcaica em 1976, numa época em que muitos livros de ficção pretendiam denunciar a brutalidade da vida política brasileira. Para a nossa literatura, os anos 70 não foram uma década perdida: basta lembrar que, nessa época, Osman Lins e Clarice Lispector publicaram obras-primas como Avalovara e $A$ hora da estrela. Mas o toque militar de recolher parecia impor um tema a alguns escritores que queriam escrever sobre o tempo presente, esse tempo que, para a literatura, parece ser um contratempo. Lavoura arcaica fugia do factual, do circunstancial, e aderia a algo que penso ser importante numa obra literária: a linguagem muito elaborada que invoca um conteúdo de verdade, uma dimensão humana, profunda e complexa. Por isso, o romance de Raduan me impressionou tanto (HATOUM in CADERNOS, 1976, p. 19-20). 
Lavoura arcaica é narrada a partir do ponto de vista de André, narrador-personagem, que por meio de uma linguagem desenfreada e convulsa, perceptível no próprio ritmo em que o texto é escrito, narra os motivos que o levaram a sair de casa.

O romance é dividido em duas partes: "A partida" e "O retorno". Na primeira parte, são narrados os acontecimentos que levaram André a abandonar a casa paterna, e na segunda, é narrado o retorno dele após seu irmão mais velho, Pedro, enquanto guardião dos ensinamentos pregados pelo pai, pedir para que ele retornasse. A forma como a obra está estruturada remete à narrativa bíblica intitulada "A parábola do filho pródigo", presente no livro de Lucas, em que também são perceptíveis duas partes: a saída do filho pródigo (primeira parte) e arrependimento e retorno deste filho ao lar (segunda parte).

Além deste diálogo com a Bíblia, especificamente com a "Parábola do filho pródigo", Nassar se apropria do conto "A volta do filho pródigo", de André Gide. Nesse trabalho intertextual, é possível perceber aproximações e distinções entre esses textos. Trataremos mais pormenorizadamente sobre esta questão adiante.

\section{Breves considerações sobre a intertextualidade}

O conceito de intertextualidade tem motivado diversos estudos que se propõem a compreender a complexidade deste termo. As primeiras noções que serviram de base para o desenvolvimento do conceito de intertextualidade surgiram a partir dos estudos realizados por Mikhail Bakhtin (1997) em Problemas da poética de Dostoiévski.

Ao fazer um estudo original acerca da obra de Dostoiévski, Bakhtin contrapõe análises feitas por outros críticos da época a respeito da linguagem, e introduz o conceito de dialogismo que, segundo ele, é uma marca essencial que caracteriza a própria linguagem e está especialmente presente na produção desse escritor russo.

Segundo Bakhtin, o dialogismo corresponde a um processo interacional entre os discursos, na qual são construídos nas relações verbais e sociais entre mais de um falante. O dialogismo é justamente este diálogo entre discursos. 
De acordo com Bakhtin, além do dialogismo, os críticos da época não observaram outro fator importante que distingue a poética de Dostoiévski das demais produções: a polifonia, cuja definição seria um embate de várias vozes no interior de um texto. Essas vozes por serem sociais podem ser contraditórias e conflituosas, pois refletem os mais variados discursos, porém cada voz tem o seu lugar na narrativa e são independentes entre si.

Para Bakhtin, foi Dostoiévski quem criou um novo gênero textual, denominado romance polifônico: "Dostoiévski é o criador do romance polifônico. Criou um gênero romanesco essencialmente novo" (BAKHTIN, 1997, p. 5). Esse tipo de romance é caracterizado por Bakhtin como uma forma inovadora de pensamento para a época, pois o mesmo se destacava pela pluralidade de vozes presentes na narrativa, as quais ele denominou polifonia.

Bakhtin considera o romance de Dostoiévski uma inovação, pois as obras até então criadas consistiam em romances monológicos nos quais apenas uma voz - a do autor prevalecia. Nesse tipo de romance, há apenas uma assimilação por parte das personagens do que é proposto pelo autor, e elas não expressam ideias próprias, ao contrário da obra de Dostoiévski que possibilita um diálogo entre as diversas vozes das personagens na narrativa. É neste diálogo que ocorre a polifonia, e os diversos discursos são trazidos à tona. Este aspecto é definido por Bakhtin como algo peculiar à obra de Dostoiévski:

A multiplicidade de vozes e consciências independentes e imisciveis e a autêntica polifonia de vozes plenivalentes constituem, de fato, a peculiaridade fundamental dos romances de Dostoiévski. (...) Dentro do plano artístico de Dostoiévski, suas personagens principais são, em realidade, não apenas objetos do discurso do autor mas os próprios sujeitos desse discurso diretamente significante. (BAKHTIN, 1997, p. 4).

Os conceitos de polifonia e dialogismo passaram a influenciar significativamente as formas de análise literária, sobretudo os romances.

A preocupação de Bakhtin com a alteridade na linguagem possibilitou o aparecimento de estudos posteriores que se propuseram a analisar este aspecto. A partir dessa concepção de diálogo com outros textos e entre interlocutores, passou-se a compreender 
que não existe voz e nem texto isolado, pois os discursos são carregados de impressões de discursos de outrem.

Partindo dos conceitos dialogismo e polifonia de Bakhtin, Julia Kristeva cunhou o termo intertextualidade para se referir ao caráter intertextual da linguagem. Em seu ensaio publicado em 1969, Introdução à Semanálise, especificamente no capítulo intitulado "A Palavra, o Diálogo e o Romance”, Julia Kristeva afirma que “[...] Todo texto se constrói como mosaico de citações, todo texto é absorção e transformação de um outro texto. Em lugar da noção de intersubjetividade, instala-se a de intertextualidade e a linguagem poética lê-se pelo menos como dupla (KRISTEVA, 1969, p. 64)".

Segundo esta autora, todo texto carrega em si marcas de outros textos que o antecederam. Ao escrever, o autor vale-se de palavras imbuídas de juízos de valor, com cargas sociais, políticas e afetivas, que já foram ditas em outro momento da história. Essa apropriação caracteriza o trabalho intertextual que o escritor realiza para compor um novo texto, com uma nova roupagem, a partir das leituras que ele fez e das influências adquiridas através do contato com essas leituras. Este trabalho intertextual pode ser percebido nos mais diversos textos da literatura, pois cada obra literária possibilita o cruzamento de diversas vozes que soam no texto.

Kristeva afirma ainda que há um constante diálogo entre textos: a existência de um determinado texto implica uma relação dialógica com outros textos já existentes, pois, “[...] A palavra (o texto) é um cruzamento de palavras (de textos) onde se lê, pelo menos, uma outra palavra (texto) (KRISTEVA, 1969, p. 64)”.

A intertextualidade pode ser percebida desde tempos antigos na literatura, apesar deste conceito ter sido instituído no final da década de 1960 e 1970. Segundo Leyla Perrone-Moisés:

O inter-relacionamento de discursos de diferentes épocas ou de diferentes áreas linguísticas não é novo, podemos mesmo dizer que ele caracteriza desde sempre a atividade poética. Em todos os tempos, o texto literário surgiu relacionado com outros textos anteriores ou contemporâneos, a literatura sempre nasceu da e na literatura. (PERRONE-MOISÉS, 1978, p. 59). 
Em outro ensaio de Perrone-Moisés (1990), intitulado "Literatura Comparada: Intertexto e Antropofagia", a autora afirma que:

A literatura nasce da literatura; cada obra nova é uma continuação, por consentimento ou contestação, das obras anteriores, dos gêneros e temas já existentes. Escrever é, pois, dialogar com a literatura anterior e com a contemporânea (PERRONE-MOISÉS, 1990, p. 94).

Assim sendo, pode-se afirmar que não há texto original, pois cada novo texto será uma continuação de textos anteriores. Entretanto, isto não diminui o valor literário dos textos, pois, "cada obra surge como uma nova voz (ou um novo conjunto de vozes) que fará soar diferentemente as vozes anteriores, arrancando-lhes novas emoções” (PERRONE-MOISÉS, 1978, p. 63).

Em seu ensaio "Kafka y sus precursores”, Borges (2007) afirma que ao ler as obras de Kakfka considerava-as singulares e originais, mas, ao comparar algumas das produções deste escritor com outras obras, de diferentes épocas, gêneros e autores, percebeu marcas textuais de sua escrita:

Yo premedité alguna vez un examen de los precursores de Kafka. A éste, al principio, lo pensé tan singular como el fénix de las alabanzas retóricas; a poco de frecuentarlo, creí reconocer su voz o sus hábitos, en textos de diversas literaturas y de diversas épocas. (BORGES, 1951, p. 25). ${ }^{1}$

Diante disso, Borges registrou, em seu ensaio, algumas produções que apresentavam semelhanças com as obras Kafkianas. Dentre elas, destacou o "Paradoxo de Zenão", de Aristóteles; um apólogo de Han Yu que se encontra na Anthologie raisonnée de la littérature chinoise (1948), de Margouliès; os textos de Kierkegaard; o poema "Ferars and Scruples" (1876), de Browning; um conto de Léon Bloy, e o conto “Carcassonne” de Dunsany. Nesses textos supracitados, Borges constatou que:

1 “Certa vez planejei um exame dos precursores de Kafka. A princípio, considerei-o tão singular quanto a fênix dos elogios retóricos, depois de alguma intimidade, pensei reconhecer sua voz, ou seus hábitos, em textos de diversas literaturas e diversas épocas". (BORGES, 2007, p. 127). 
Si no me equivoco, las heterogéneas piezas que he enumerado se parecen a Kafka; si no me equivoco, no todas se parecen entre sí. Este último hecho es el más significativo. En cada uno de esos textos está la idiosincrasia de Kafka, en grado mayor o menor, pero si Kafka no hubiera escrito, no la percibiríamos; vale decir, no existiría. $^{2}$

Tal afirmação de Borges nos aponta para o fato de que, ao escrever, o autor cria os seus precursores que irão proporcionar aos leitores a oportunidade de descobrir novos sentidos: "El hecho es que cada escritor crea sus precursores. Su labor modifica nuestra concepción del pasado, como ha de modificar el futuro.” (BORGES, 1951, p. 26). ${ }^{3}$

As constatações realizadas por Borges corroboram as ideias desenvolvidas por Kristeva a respeito da intertextualidade, segundo a qual os textos constituem uma rede de conexões, razão pela qual a inserção de elementos dentro do texto constrói uma rede dialógica da escritura-leitura.

\section{“A parábola do pródigo": Intertextualidade em Lavoura arcaica de Nassar e "A volta do filho pródigo" de Gide}

Pode-se perceber, em Lavoura arcaica, que Raduan Nassar soube apropriar-se de muitos textos que fizeram parte de seu percurso como leitor. Em nota escrita na primeira edição de Lavoura arcaica, e suprimida nas demais edições, o próprio Nassar afirma que, ao escrever seu romance, bebeu em outras fontes, como o Livro das Mil e Uma Noites, a Bíblia e "A volta do filho pródigo", de André Gide.

Leitor de textos da Bíblia Sagrada, Nassar faz uma releitura da parábola bíblica do "Filho pródigo", presente no livro de Lucas, e elabora seu próprio texto. Além disso, ele

\footnotetext{
${ }^{2}$ Se não me engano, as peças heterogêneas que enumerei se parecem com Kafka; se não me engano, nem todas se parecem entre si. Este último fato é o mais significativo. Em cada um desses textos reside a idiossincrasia de Kafka, em grau maior ou menor, mas se Kafka não tivesse escrito, não a perceberíamos; ou seja, ela não existiria. (BORGES, 2007, p. 129).

3 "O fato é que cada escritor cria seus precursores. Seu trabalho modifica nossa concepção do passado, assim como há de modificar o futuro” (BORGES, 2007, p. 130).
} 
se apossa de outras parábolas presentes nos livros de Matheus, Marcos, Lucas e João, como "A Dracma Perdida"; "A parábola do semeador" e "A ovelha desgarrada". Estas narrativas bíblicas eram proferidas por Jesus e tinham como principal objetivo doutrinar e ensinar as pessoas acerca dos principais valores religiosos. De uma forma geral, as parábolas bíblicas se caracterizam por uma linguagem simples nas quais são narrados exemplos que faziam parte do cotidiano das pessoas para ilustrar temas complexos como a salvação, o perdão e o amor.

Essas parábolas podem ser percebidas em Lavoura arcaica, principalmente nos discursos pregados pelo pai de André, o narrador-personagem. O romance é dividido em duas partes: "A partida" e "O retorno", e sua estrutura se assemelha à parábola "O Filho Pródigo".

A parábola bíblica narrada no livro de Lucas, capítulo 15 e versículos 11 a 32, iniciase relatando que um pai possuía dois filhos, que não são nomeados, o mais velho e o mais novo. Este decide sair de casa e pede ao pai que lhe dê uma parte da herança que lhe pertencia por direito. Não são descritos os motivos que levaram este filho a rebelar-se da casa paterna, mas o fato de ele pedir a herança pode ser analisado como uma blasfêmia não só contra o pai, mas contra toda a cultura judaica em que estavam inseridos, segundo a qual, o filho só tem direito à herança quando seu pai morre. E o filho, enquanto o mais novo, mostra-se impaciente ao querer usufruir de algo cujo tempo ainda não era chegado, uma vez que seu pai ainda não havia falecido.

Na narrativa bíblica não é relatada a reação do pai diante da atitude do filho, mas decide conceder-lhe o pedido, e o pródigo parte para longe do lar e gasta todo o dinheiro exigido ao seu pai, em terras estrangeiras. O fato de desperdiçar a herança recebida em terras estrangeiras torna a transgressão do pródigo ainda mais severa, pois segundo a cultura judaica isso era um insulto. O pródigo passa por situações de abandono, fome e humilhações e, humildemente, decide retornar ao lar e pedir perdão ao pai:

E disse: Um certo homem tinha dois filhos. ${ }^{12} \mathrm{E}$ o mais moço deles disse ao pai: Pai, dá-me a parte da fazenda que me pertence. E ele repartiu por eles a fazenda. ${ }^{13} \mathrm{E}$, poucos dias depois, o filho mais 
novo, ajuntando tudo, partiu para uma terra longínqua e ali desperdiçou a sua fazenda, vivendo dissolutamente. ${ }^{14} \mathrm{E}$, havendo ele gastado tudo, houve naquela terra uma grande fome, e começou a padecer necessidades. ${ }^{15} \mathrm{E}$ foi e chegou-se a um dos cidadãos daquela terra, o qual o mandou para os seus campos a apascentar porcos. ${ }^{16}$ E desejava encher o seu estômago com as bolotas que os porcos comiam, e ninguém lhe dava nada. ${ }^{17} \mathrm{E}$, caindo em si, disse: Quantos trabalhadores de meu pai têm abundância de pão, e eu aqui pereço de fome! ${ }^{18}$ Levantar-me-ei, e irei com meu pai, e dir-lhe-ei: Pai, pequei contra o céu e perante a ti. ${ }^{19}$ Já não sou digno de ser chamado teu filho, faze-me como um dos teus trabalhadores. (Lc 15, 11-19) ${ }^{4}$.

O pródigo da parábola retorna ao lar completamente humilde e arrependido. O pai, misericordioso, opta por acolher o filho arredio com uma grande festa e tal atitude gera revolta no irmão mais velho que se sente inconformado em ver que seu irmão havia ganhado uma festa em celebração do seu retorno, mesmo após a falta que ele havia cometido contra a família. O pai explica ao filho indignado que era necessário comemorar a volta do filho que estava morto e voltou à vida: “32 Mas era justo alegrarmo-nos e regozijarmo-nos, porque este teu irmão estava morto e reviveu; tinha-se perdido e foi achado" (Lc 15, 31).

Esta narrativa bíblica serviu-se como fonte para diversas produções literárias como "A volta do Filho Pródigo", de André Gide, e Lavoura arcaica, de Raduan Nassar. Estas narrativas apresentam semelhanças e distinções entre si. Em relação à estrutura, percebese que, enquanto a parábola bíblica e Lavoura arcaica apresentam duas partes, o texto de Gide se encontra dividido em cinco: "O filho Pródigo"; "A reprimenda do Pai"; "A reprimenda do filho"; "A mãe" e "O diálogo com o irmão mais novo". Além disso, a estrutura familiar desses textos é diferente entre si. Na parábola aparecem apenas o pai e seus dois filhos, enquanto que em Gide há a inserção de mais duas personagens: a mãe e um filho caçula. Nassar se apropriou dessa inovação adotada por Gide e inseriu em sua obra a mãe, o filho caçula e quatro filhas. ${ }^{4}$ Utiliza-se aqui e no restante do artigo, a edição da Bíblia Sagrada traduzida em português por João Ferreira de
Almeida, publicada pela Sociedade Bíblica do Brasil, Rio de Janeiro, 2009. 
Apesar de essas narrativas trazerem a imagem de um filho que sai de casa e retorna ao lar, o retorno é visto mediante perspectivas diferentes. Na parábola de Jesus, o filho pródigo retorna humilhado, arrependido, anseia servir ao pai, e é recebido por este com uma grande festa. Em Gide, o retorno é narrado ironicamente, pois o filho que retorna o faz devido à fome, ao frio, e à indolência, porém o pai também o recebe com uma festa:

- Então, que te fez voltar? Fala.

— Não sei. A indolência, talvez.

— A indolência, meu filho! Então, não foi o amor?

— Pai, já vos disse, jamais vos amei tanto quanto no deserto. Mas estava cansado, cada manhã, de prover minha subsistência. Em casa, pelo menos, se come bem.

— Sim, os servidores provêm todo o necessário. Com que, então, o que te trouxe de volta foi a fome.

— É possível também que a enfermidade, a covardia..." (GIDE, 2015, p. 131).

Nassar apresenta em sua obra um filho pródigo que retorna ao lar não por vontade própria, mas por intermédio de seu irmão mais velho, Pedro, que, em nome da família, decide resgatá-lo. Ao regressar, este filho pródigo não sente alívio, nem arrependimento, e não sabe quais foram os motivos que o levaram a voltar para o seio da família: “[...] eu tinha os olhos nessa direção, e me perguntava pelos motivos da minha volta, sem conseguir contudo delinear os contornos suspeitos do meu retorno [...]” (NASSAR, 1989, p. 170). Entretanto, assim como na parábola bíblica, e em Gide, em Nassar, o filho pródigo também é recebido com uma festa para comemorar seu retorno.

A figura do pai nessas narrativas é diferente entre si. Em Lucas, o pai, enquanto representante do amor de Deus pelo homem, mostra-se misericordioso e piedoso para com o filho arrependido, assim como em Gide. Entretanto, em Nassar, o pai, enquanto detentor da ordem, é autoritário e severo.

Os sermões são pregados pelo pai, em Nassar, a fim de manter a disciplina no seio familiar, enquanto que, em Gide, a reprimenda é feita pelo irmão mais velho do pródigo que instrui o pai a repreendê-lo: “- Talvez tenha te falado com dureza. Foi teu irmão que o quis; é ele quem dita a lei aqui. Foi ele que me intimou a dizer-te: "Fora da Casa; não há 
salvação para ti." “(GIDE, 2015, p. 131). Em Lavoura arcaica, o irmão mais velho também prega o discurso da ordem, mas se mostra afetivo com André, o seu irmão desgarrado a quem ele sente-se no dever de resgatar. O sentimento de afeição pelo pródigo é também representado pela imagem da mãe que demonstra uma relação afetiva com este filho. André relata as trocas de carinhos recebidas pela mãe desde a infância, e suas memórias comprovam o quanto o afago da mãe simbolizava para ele o amor da figura materna:

[...] e só esperando que ela entrasse no quarto e me dissesse muitas vezes "acorda, coração" e me tocasse muitas vezes suavemente o corpo até que eu, que fingia dormir, agarrasse suas mãos num estremecimento, e era então num jogo sutil que nossas mãos compunham debaixo do lençol, e eu ria e ela cheia de amor me asseverava num cicio "não acorda teus irmãos, coração" [...](NASSAR, 1989, p. 25).

Este afeto simbolizado pela mãe também se percebe na narrativa de Gide na qual, ao retornar, o filho decide revelar para sua progenitora os verdadeiros motivos que o levaram a abandonar a casa: “- Buscava... Quem eu era”. (GIDE, 2015, p. 135).

Além da inserção da mãe, é possível perceber a presença marcante de um filho caçula tanto na família apresentada em Gide quanto na que se revela em Nassar, mas que é inexistente no texto de Lucas. O filho caçula representa na narrativa gideana a possibilidade de repetição da fuga já realizada pelo pródigo, todavia, com o desejo de percorrer os caminhos trilhados pelo irmão e não mais retornar. Diferentemente de seu irmão que retorna para o lar, o caçula não quer fracassar e, após o diálogo com o pródigo que narra as desventuras enfrentadas durante a fuga, decidiu percorrer os caminhos que o levariam para longe de casa. O pródigo, ao constatar o desejo do caçula de fugir, decide apoiá-lo e encorajá-lo a fim de que alcance o sucesso que ele mesmo não obteve. O desfecho da narrativa gideana é marcado pela partida de outro membro da família, o filho caçula que parte, sem alvoroço e antes do alvorecer do dia: “[...] - A hora está chegando. O céu empalidece. Parta sem ruído. Vamos! Abrace-me, meu caro irmão: você leva todas as minhas esperanças. Tenha força: esqueça-me. Que você possa nunca mais voltar... Saia sem ruído. Eu seguro a candeia..." (GIDE, 2015, p. 143). 
Em Nassar, o caçula também possui o desejo de fugir e em diálogo com André revela que sempre foi um admirador da fuga de seu irmão e que almejava seguir o mesmo caminho: “- Só foi você partir, André, e eu já vivia empoleirado lá na porteira, sonhando com estradas, esticando os olhos até onde podia, era só na tua aventura que eu pensava..." (NASSAR, 1989, p. 178).

A inserção do filho caçula como personagem da narrativa e a concretização de sua fuga violam o texto bíblico. Em Nassar, além do desejo de fuga do filho caçula, há a inserção de tabus que giram em torno da sexualidade, como a questão do incesto, que foi discutida por meio da relação do narrador-personagem com a sua irmã, Ana. No romance, André alimenta um sentimento ardente pela sua irmã que ultrapassa os laços fraternais e, não suportando os limites impostos pelo patriarca e pela cultura que o cercavam, decide partir para longe do lar. Seu retorno, diferentemente do texto bíblico, acaba desencadeando um final trágico: o patriarca mata sua filha com um só golpe, e demole "o que levou milênios para se construir”: “[...] mas era o próprio patriarca, ferido nos seus preceitos, que fora possuído de cólera divina (pobre pai!), era o guia, era a tábua solene, era a lei que se incendiava [...]" (NASSAR, 1989, p. 191).

Após a atitude do pai, André, por meio de questionamentos, conclui que a razão e os sermões do patriarca eram inconsistentes, pois o próprio transgrediu os mandamentos que pregava. Ao final da narrativa, André se apropria do mesmo discurso paterno, para mostrar o quanto eram contraditórios todos os ensinamentos por ele proferidos:

Em memória de meu pai, transcrevo suas palavras: "e circunstancialmente, entre posturas mais urgentes, cada um deve sentar-se num banco, plantar bem um dos pés no chão, curvar a espinha, fincar o cotovelo do braço no joelho, e, depois, na altura do queixo, apoiar a cabeça no dorso da mão, e com os olhos amenos assistir ao movimento do sol e das chuvas e dos ventos, e com os mesmos olhos amenos assistir á manipulação misteriosa de outras ferramentas que o tempo habilmente emprega em suas transformações, não questionando jamais sobre seus desígnios insondáveis, sinuosos, como não se questionam nos puros planos das planícies as trilhas tortuosas, debaixo dos cascos, traçadas nos pastos pelos rebanhos: que o gado sempre vai ao poço”. (p. 193-194). 
Ao invés de o retorno do filho arredio proporcionar o reestabelecimento da ordem, como parece acontecer em Lucas, em Nassar, este retorno realça as inquietações presentes na família de André, despertadas no momento de sua partida. A fuga de André acabou abalando as estruturas de sua família arcaica, e trazendo à tona as contradições do discurso paterno que objetivava a manutenção da ordem e da razão na família.

Percebe-se que Raduan Nassar apropriou-se e incorporou, em Lavoura arcaica, muitos elementos da narrativa bíblica e do conto de Gide, realizando, desta forma, um diálogo entre esses textos. É justamente este trabalho realizado por Nassar que é definido como intertextualidade.

\section{Considerações finais}

As ideias de dialogismo e polifonia propostas por Mikhail Bakhtin contribuíram para a definição e compreensão do conceito de intertextualidade proposto por Julia Kristeva. A partir de suas reflexões teóricas a respeito da linguagem e do discurso, a autora introduz na crítica textual a noção de intertextualidade, que se refere ao constante diálogo entre textos. Esta troca de experiências textuais pode ser percebida desde tempos remotos na literatura, uma vez que, muitos textos da antiguidade clássica serviram-se de fonte primordial para composições de grandes obras literárias. Dentre esses textos antigos encontra-se a Bíblia, um dos livros mais utilizados para composições literárias.

A narrativa bíblica intitulada "A parábola do filho pródigo" foi reaproveitada por diversos autores não só na literatura, mas também em outras áreas como a música, o cinema e as artes em geral. A temática do filho que se rebela contra os preceitos do pai para percorrer caminhos desconhecidos parece ter atraído e influenciado a escrita de alguns escritores como André Gide e Raduan Nassar. Em Lavoura arcaica, esta releitura da parábola de Jesus foi protagonizada por André sob uma nova perspectiva, distanciando-se muitas vezes do texto fonte. Este distanciamento não tem a pretensão de rejeitar a fonte bíblica, mas possibilitar que novas perspectivas emerjam a partir da criação literária. 
Diante disso, pode-se afirmar que a intertextualidade é uma marca de grande valor literário em Lavoura arcaica, na qual Nassar, além de transgredir a narrativa bíblica, apropriase de outros textos literários para compor algo totalmente novo e singular.

\title{
LAVOURA ARCAICA, BY RADUAN NASSAR, AND \\ "THE RETURN OF THE PRODIGAL SON", BY ANDRÉ GIDE: AN INTERTEXTUAL READING
}

\begin{abstract}
This article presents an analysis of Archaic farming (1975), Inaugural novel by Brazilian writer Raduan Nassar, through the concepts of dialogism and polyphony, as advocated by Mikhail Bakhtin (1972), and by the concept of intertextuality, instituted by Julia Kristeva (1969) and discussed by literary critics Perrone-Moisés (1978) and Borges (2007). With a singular writing, Nassar takes from the biblical narrative "The parable of the Prodigal Son", present in the book of Luke, and the tale "The Return of the Prodigal Son", by André Gide, to elaborate something innovative. In this intertextual work, carried out by Nassar in Lavoura arcaica, it is possible to perceive approximations and distinctions of the aforementioned texts.
\end{abstract}

KEYWORDS: André Gide; Intertextuality; Lavoura arcaica; Raduan Nassar; The return of the prodigal Son.

\section{REFERÊNCIAS}

BAKHTIN, Mikhail. Problemas da poética de Dostoiévski. 2. ed. Rio de Janeiro: Forense Universitária, 1997.

BIBLÍA. Português. Bíblia Sagrada. Trad. João Ferreira de Almeida. Sociedade Bíblica do Brasil: Rio de Janeiro, 2009.

BORGES, Jorge Luis. Kafka y sus percursores. In: Obras completas. 17. ed. Bueno Aires: Emecé Editores, 2007. p.107-109.

GIDE, André. A volta do filho pródigo. In: A volta do filho pródigo. Trad. Ivo Barroso. Rio de Janeiro: Nova Fronteira, 2015. p. 123-144.

HATOUM, Milton. Os companheiros. In: Cadernos de literatura brasileira, n.2, set. 1996. Semestral.

KRISTEVA, Julia. A palavra, o Diálogo e o Romance. In: Introdução à semanálise. São Paulo: Editora Pespectiva, 1969. p. 61-90.

NASSAR, Raduan. Lavoura arcaica. 3. ed. São Paulo: Companhia das Letras, 1989.

PELLEGRINI, Tânia. Despropósitos: estudos de ficção brasileira contemporânea. São Paulo: Annablume; Fapesp, 2008. p. 15-52. 
PERRONE-MOISÉS, Leyla. Literatura Comparada: Intertexto e Antropofagia. In: . Flores da escrivaninha: ensaios. São Paulo: Companhia das Letras, 1990. p. 91-99.

SCOLLHAMMER, Karl Erik. Fiçcão brasileira contemporânea. Rio de Janeiro: Civilização Brasileira, 2009.

Crítica e Intertextualidade. In: Texto, crítica, escritura. São Paulo: Ática, 1978. p. 58-76.

Recebido em: 01/06/2018.

Aprovado em: 04/08/2018. 